\title{
Multilevel analysis of male fertility behaviour in Nigeria
}

\author{
Ololade G Adewole ${ }^{1}$, Sunday A. Adedini ${ }^{2,3}$ \& Luqman A. Bisiriyu ${ }^{2}$ \\ ${ }^{1}$ National Centre for Technology Management, Obafemi Awolowo University, \\ Ile-Ife, Nigeria \\ ${ }^{2}$ Department of Demography and Social Statistics, Obafemi Awolowo University, \\ Ile-Ife, Nigeria \\ ${ }^{3}$ Programme in Demography and Population Studies, Schools of Public Health \\ and Social Sciences, University of the Witwatersrand, \\ Johannesburg, South Africa \\ E-mail: ololadegrace@yahoo.com
}

\begin{abstract}
Context/Background: Fertility level in Nigeria remains high and currently, it stagnating at about six children per woman. Demographic literature had established the existence of preponderance of factors sustaining a high level of fertility in the country. Most previous studies on fertility had focused on women, and a few that examined male fertility behaviour focused mainly on individual-level factors, ignoring the influence of community contexts. This study, therefore, examined the influence of an individual, household and community level factors on male fertility behaviour in Nigeria.

Data source and Methods: The study used male data from 2013 Nigeria Demographic and Health Survey (DHS).

Results: Results showed that community variables like region, ethnic diversity, community family-size norm and community-level of education significantly influenced male fertility behaviour in Nigeria $(p<0.05)$.

Conclusion: The study thus established community contexts as an important factor influencing male fertility behaviour, and this factor must be taken into consideration in the efforts to reduce the fertility level in Nigeria.
\end{abstract}

Keywords: Multilevel analysis; Male fertility behaviour; Community contexts; Nigeria.

\section{Introduction}

Countries with high fertility are increasingly concentrated in sub-Saharan Africa while countries with low fertility are becoming more diverse geographically. According to the United Nations, Department of Economic and Social Affairs, Population Division (2014), countries like Asia, Latin America and the Caribbean were identified as lowfertility countries. In Africa however, most countries in the Central and Western Africa, including Niger, Mali and Nigeria are predominantly high fertility countries. Fertility level remains very high in Nigeria and currently, it stagnating at about six children per woman. Therefore, there is the existence of preponderance of factors responsible for high level of fertility in Nigeria.

Studies on fertility have been normally attributed to women without consideration for men (Osasuwa \& Ugal, 20l8; Udjo, 20l8). Biology, nevertheless, dictates that females and males must be involved in bearing of children. The male sex as a whole has an equivalent amount of contribution to reproduction as the female counterpart. In fact, the variation of each individual male's contribution to generating offspring is even considered as significantly greater than that of the female.

Most prior researchers have mainly focused on fertility dynamics and behaviour of women. Moreover, the various UN conferences particularly the International Conference on Population and Development (ICPD) first at Bucharest, 1974, second at Mexico, 1984 and the third which was convened in Cairo, Egypt, 1994 adopted the Programme of Action, which emphasized the fundamental role of women's interests in population matters and introduced the concepts of sexual and reproductive health and reproductive rights (Odimegwu, Pallikadavath, \& Adedini, 20I3). 
Also, family planning policies stressed women's role in the contraceptive use and family planning. Besides, increasing women's labour force participation and educational attainments are considered as key means of lowering fertility in many countries (Rindfuss et al., 1996; Smith-Lovin and Tickamyer, 1978). However, most of these studies and policies largely ignore the fertility behaviour of men. The lack of empirical research about men stems from problems such as linking fathers and their biological offspring, biological differences in male reproductive behaviour as compared to women, missing data and concerns about the quality of existing data sources.

The fact that the growth rate is still high (PRB, 2016), fertility still remains a serious issue for research and policy in Nigeria and there is need to generate new and more reliable scientific evidence on how best to tackle the key determinants of fertility in the country and also to change our tradition of focusing majorly on women in empirical research. A few studies that have examined male fertility behaviour mainly focused on an individual and household level characteristics. Meanwhile, most of these studies largely ignore the influence of community context on male fertility behaviour.

This study makes use of the multilevel approach to tease out the contextual effects on male fertility behaviour in Nigeria. The approach is a methodological framework which formulates the micro-macro relationships existing between individuals and their contexts. Evidence from other studies suggested that community contexts had influences on demographic outcomes, such as childhood mortality (Adedini, 2013); maternal mortality (Ononokpono and Odimegwu, 20I4); and contraceptive use (Imasiku et al, 20l4). This study seeks to examine the influence of community contexts on fertility behaviour of men in Nigeria. The main question is "what are the individual, household and community level factors associated with male fertility behaviour in Nigeria?

\section{Literature review and theoretical framework}

Empirical studies that were used to explain changes in human fertility rarely included men. A few other studies shifted their research focus on men's role in fertility decision-making and family planning to more industrialised societies, such as United States (Zhang, 20II). It was well documented that men's general knowledge and attitudes concerning the ideal family size, sex preference of children, ideal spacing between childbirths and contraceptive method greatly influenced women's preferences and opinions (Mbizvo and Adamchak, 1991, Mistiket al, 2003; Odu et al., 2005.). However, fertility and family planning researches and programmes ignored men's roles in the past, focusing on women's behaviours (Becker, 1996 and Oyediran et al, 2002) while family planning services were presented within the context of maternal and child health (Mason and Lynam, 1992).

Few researchers addressed the determinants of male fertility. Morris (1993) studied the determinants of male fertility through surveys of young adult reproductive health in Latin America. Data were obtained from health surveys conducted since 1985 in Jamaica, the Dominican Republic, Costa Rica, and 10 Latin American cities and from demographic surveys in Panama, Brazil, Paraguay, Honduras, El Salvador, and Haiti. The health surveys pertained to a sample of men and women aged 15-24 years, while the demographic surveys only included women aged 15-24 years. Level of analysis restricted only to individual-level variables.

Also, a review of Demographic Health Surveys (DHS) in West African countries revealed that men from this sub-region, especially in Cameroon, Burkina Faso and Senegal desire and subsequently have large family sizes (Farzaneh, 1996). In Niger and Cameroon, the Ideal Family Sizes (IFS) were I 2.6 and II.2 respectively. In many Countries of West Africa, on the average, husbands ideally wanted at least three more children than their wives. The desire for many children by men in West African countries, Nigeria inclusive, is driven largely by economic, sociocultural, egoistic and religious factors and this has impacted negatively on the demographic and socioeconomic situation in the region (Odu et al, 2005).

Also, Schounmaker (2013) used Demographic and Health Survey data to evaluate "to what extent and with which methods", the DHS data in sub-Saharan Africa could be used to measure levels and patterns of male fertility and secondly, to provide a broad overview of male fertility levels and patterns in subSaharan Africa. The results showed that DHS data could be used to calculate age-specific male fertility rates and male total fertility rates (TFR) in different ways. However, the study by Schounmaker only calculated rates of fertility behaviour.

Odu et al., (2005) studied the reproductive behaviour and determinants of fertility among men in a semi-urban Nigerian community. The study was conducted to examine the reproductive behaviour and determine the determinants of men fertility at Ganmo, a suburban community on the outskirts of Ilorin, Nigeria. A proportionate sampling procedure was employed in selecting the required number of men from each of the 32 compounds that make up the community. The level of analysis by Odu et al was restricted to individual-level variables. Household and community levels variables were not considered.

Billy (1992) examined the role of a wide range of community characteristics in determining the risk of 
married and non-married non-black women having a live birth. It was found that context affects the risk of both a marital and non-marital birth, although the number of contextual influences is greater for nonmarried women. Almost all community characteristics operate independently of individuallevel characteristics of the woman.

Likewise, De rose and Racioppi (200I) conducted a research on female samples among 13 European countries to explain voluntary low fertility using a multilevel approach different from the formal pattern of studying fertility at the individual level. They narrowed the contextual factors to just two, modernisation and equality of gender system because of the lack of multilevel design in most social and demographic surveys used for this study, despite its clear importance for the correct application of the models. The result showed that voluntary low fertility was reduced by a greater modernisation in social and demographic conditions and by a favourable gender system. Nonetheless, the contextual factors were related to female studies. Also, Grace and Carr (2009) explored the impact of an individual, household and community on fertility behaviour in Peten, Guatemala. The results of the analysis highlighted the significance of an individual land use variables even after adjustments for socioeconomic status and ethnicity.

This study was guided by Bongaarts model framework (1978) for analysing the proximate determinants of fertility as well as Easterlin and Crimmins' theory (1985) of fertility revolution. The later explained a supply-demand analysis which seeks to explain fertility decline in the light of a more general societal transformation called the modernisation process. The process consists of structural changes that affect the economic, social and political structures of the society in which they occur. The former (Bongaarts model framework) enumerated proximate determinants of fertility. These determinants are the behavioural and biological factors that influence fertility directly. Cultural, psychological, economic and social, and environmental factors affect fertility indirectly through these proximate determinants. The framework was for female fertility but is being adapted for male fertility. While the later builds on the former to provide a logical framework for interpreting the effect of individual, family and community characteristics on male fertility.

In this present study, Bongaart model and Easterlin and Crimmins' theory was adapted for male fertility analysis. Demographic studies assume that male fertility behaviour is different from that of female in many ways: men presumably have a longer reproductive lifespan and tend to start their fertility career later than women do; the variety of the number of biological children born to men is assumingly larger compared to that of women, and men tend to underreport their fertility outcomes (Alich, 2007). All these aspects are rather neglected in empirical research and are often considered obstacles to incorporating men in fertility and family demography. However, the analysis of male fertility can complement the analysis of female fertility and their determinants may differ (Zhang, 20I I).

\section{Data and method}

The study employed secondary data which was extracted from the male data of 2013Nigeria Demographic and Health Survey (NDHS). The data set is a nationally representative data collected from men aged 15-49 with a weighted sample size of 17,359 being interviewed from 18,229 eligible men.

The variables at the individual level include socioeconomic and demographic characteristics of men. The socio-economic characteristics include education, religion, occupation, ethnicity and usage of media which was measured by frequency of reading newspaper, the frequency of listening to radio and frequency of watching television. The demographic characteristics include age, desired family size and child preference. Important selected household-level variables which could influence men fertility behaviour include; income level, forms of marriage and number of spouses. The variables at the community level include; region of residence, place of residence, ethnic diversity (The extent of diversity in the community where respondents live in terms of ethnic composition), community level of education (Proportion of men who had at least secondary education in the community), community media access (Proportion of men who had access to newspaper/magazine, radio and television), community poverty level (Proportion of men with low income level), community family size norm (Proportion of men with high family-size norm in community).

All community-level characteristics were constructed at the level of the primary sampling unit, except the region of residence and place of residence. These were defined as the proportion of men who had particular attributes in the community. Each of these constructed community characteristics was divided into three categories as (i) low (ii) middle and (iii) high. Low represents the low concentration of men with particular characteristics and 'high' represents a high concentration of men with a set given characteristics in the community.

Three levels of analysis were done. The first was a univariate analysis which described some of the characteristics of the respondents. The second was a 
bivariate analysis which showed the mean CEB of men by some of the characteristics and thirdly, multivariate analysis was done using Stata statistical package (version 12.0). A regression model was fitted using multilevel Poisson regression analysis to evaluate the importance of individual, household and community characteristics to fertility. The multilevel Poisson regression analysis was performed using the generalized linear latent and mixed models (GLLAMM) procedure implementable in Stata.

Measures of association (i.e. fixed effects) were expressed in this study as an exponential coefficient). The random effects which were regarded as measures of variations in children ever born across communities were expressed in this study as intraclass correlation (ICC) (or variance partition coefficient (VPC), and proportional change in variance (PCV). The precision of random effects was determined by the standard error (SE) of the covariates. Regression diagnostic using Akaike Information Criteria (AIC) was done to determine the goodness of fit of the consecutive models. AIC (introduced by Hitrotugu Akaike in 197I), measures the relative goodness of fit of the statistical model. Boco (2010) in his work noted that the lower value of AIC indicates a better fit.

In all, five models were used in this work. Model $0,1,2,3$ and 4 . Model 0 is an empty model. It contained no explanatory variable but focused on decomposing the total variance into individual and community-level components. Model I considered only the individual-level variables which incorporated both the household and the intervening variables into the multilevel analysis. Model 2 considered only the community-level variables which were used to examine the effect of community-level factors on men's fertility, independent of other factors. Model 3 is the full model that incorporated all variables into the multilevel analysis while model 4 is the final model which incorporated only variables that were significant using stepwise forward selection.

\section{Results}

\section{Descriptive statistics}

As shown in Table I, it was observed that the highest proportion of the respondents were young men 15 24 years $(37.5 \%)$ while close to half of the respondents have a secondary level of education $(47.7 \%)$. The survey further showed that half of the respondents were Muslims (51.6\%) and quarter of the respondents was in the category of the richest $(25.0 \%)$. A bulk of the respondents $(83.2 \%)$ had monogamy forms of marriage.

\section{Bivariate analysis}

Table 2 revealed the average number of children ever born according to their background characteristics. Men with no education had the highest CEB (3.5) while men with higher education had the lowest CEB (I.8). The survey revealed that respondents who reside in the communities with few men that have low access to media have more children ever born (2.9) than those who reside in the community with high access to media (I.6). 
Table I Percentage distribution of study sample by background characteristics

\begin{tabular}{|c|c|c|}
\hline Variables & Frequency & percentage \\
\hline \multicolumn{3}{|l|}{ Age } \\
\hline $15-24$ & 6511 & 37.5 \\
\hline $25-34$ & $517 \mid$ & 29.8 \\
\hline 35 and above & 5676 & 32.7 \\
\hline \multicolumn{3}{|c|}{ Educational Level } \\
\hline No education & 3685 & 21.2 \\
\hline Primary & 2907 & 16.7 \\
\hline Secondary & 8281 & 47.7 \\
\hline Higher & 2486 & 14.3 \\
\hline \multicolumn{3}{|l|}{ Religion } \\
\hline Christianity & 8195 & 47.4 \\
\hline Muslim & 8907 & 51.6 \\
\hline Traditional & 178 & 1.0 \\
\hline \multicolumn{3}{|c|}{ Desired family size } \\
\hline $0-2$ children & 517 & 3.2 \\
\hline 3-4 children & 4642 & 28.3 \\
\hline $5+$ children & 11256 & 68.6 \\
\hline \multicolumn{3}{|l|}{ Wealth index } \\
\hline Poorest & 2862 & 16.5 \\
\hline Poorer & 2992 & 17.2 \\
\hline Middle & 3338 & 19.2 \\
\hline Richer & 3835 & 22.1 \\
\hline Richest & 4332 & 25.0 \\
\hline \multicolumn{3}{|l|}{ Regions } \\
\hline North Central & 2685 & 15.5 \\
\hline North East & 2515 & 14.5 \\
\hline North West & 5185 & 29.9 \\
\hline South East & 1686 & 9.7 \\
\hline South South & 2445 & 14.1 \\
\hline South West & 2844 & 16.4 \\
\hline \multicolumn{3}{|c|}{ Community poverty } \\
\hline Low & 5123 & 29.5 \\
\hline Medium & 5274 & 30.4 \\
\hline High & 6962 & 40.1 \\
\hline \multicolumn{3}{|c|}{ Proportion with high family-size norm in community } \\
\hline Low & 4143 & 23.9 \\
\hline Middle & 6132 & 35.3 \\
\hline High & 7084 & 40.8 \\
\hline \multicolumn{3}{|c|}{ Community media access } \\
\hline Low & 4832 & 27.8 \\
\hline Middle & 5919 & 34.1 \\
\hline High & 6608 & 38.1 \\
\hline
\end{tabular}

The distribution of the average number of children ever born based on their wealth status shows that the poorest have the highest number of children ever born (2.7). The relationship was significant at $\mathrm{F}=$ 169.7, $p=0.000$. Community poverty is another significant factor in the number of children ever born at $\mathrm{F}=340.2, p=0.000$. Respondents who live in the community with few men that earn low income have 4409 the number of children on the average (3.I) than those who live in communities with the high number of men that earn low income (I.6).

\section{Multivariate analysis}

Table 3 shows the multivariate analysis. The analysis was used to examine how variation was built up from various levels of individual, household and http://aps.journals.ac.za 
community-variables. A separate analysis was done to examine the relationships among children ever born and characteristics at various levels of operations. Fixed effects and random effects which are important correlation) and proportional change in variance are good measures that provide a good understanding of contextual determinants of individual health. In this section, measures of variation representing the extent to which men in the same neighbourhood or concepts in the multilevel analysis were employed in results interpretation.

In this modelling, measures of variations such as variance partition coefficient (or intra-class community are exposed to the same situations such as low (or high level) of poverty, education, media access, family norm and ethnic diversity are discussed.

Table 2: Mean CEB by background characteristics

\begin{tabular}{|c|c|c|c|c|}
\hline Variables & $\mathbf{N}$ & $\bar{X}_{\text {(SD) }}$ & $\begin{array}{c}F \\
\text { (ANOVA) }\end{array}$ & $\mathbf{P}$ \\
\hline \multicolumn{5}{|l|}{ Age } \\
\hline $\begin{array}{l}\text { I5-24 } \\
25-34 \\
35 \text { and above } \\
\text { Educational Level }\end{array}$ & $\begin{array}{l}6548 \\
5131 \\
5680\end{array}$ & $\begin{array}{l}0.1(0.4) \\
1.4(1.8) \\
5.3(3.8)\end{array}$ & 7567.5 & 0.000 \\
\hline $\begin{array}{l}\text { No education } \\
\text { Primary } \\
\text { Secondary } \\
\text { Higher } \\
\text { Religion }\end{array}$ & $\begin{array}{l}3354 \\
2979 \\
8390 \\
2636\end{array}$ & $\begin{array}{l}3.5(4.1) \\
3.2(3.7) \\
1.3(2.5) \\
1.8(2.8)\end{array}$ & 533.0 & 0.000 \\
\hline $\begin{array}{l}\text { Christianity } \\
\text { Muslim } \\
\text { Traditional } \\
\text { Desired family size }\end{array}$ & $\begin{array}{c}8974 \\
8134 \\
174\end{array}$ & $\begin{array}{l}1.6(2.6) \\
2.6(3.8) \\
3.9(4.4)\end{array}$ & 210.3 & 0.000 \\
\hline $\begin{array}{l}0-2 \text { children } \\
3-4 \text { children } \\
5+\text { children } \\
\text { Wealth index }\end{array}$ & $\begin{array}{c}470 \\
4676 \\
11309\end{array}$ & $\begin{array}{l}1.1(2.2) \\
1.0(1.8) \\
2.6(3.6)\end{array}$ & 455.5 & 0.000 \\
\hline $\begin{array}{l}\text { Poorest } \\
\text { Poorer } \\
\text { Middle } \\
\text { Richer } \\
\text { Richest } \\
\text { Regions }\end{array}$ & $\begin{array}{l}2646 \\
3033 \\
3538 \\
4042 \\
4100\end{array}$ & $\begin{array}{l}3.2(4.2) \\
2.7(3.7) \\
2.1(3.3) \\
1.8(2.9) \\
1.4(2.2)\end{array}$ & 169.7 & 0.000 \\
\hline $\begin{array}{l}\text { North Central } \\
\text { North East } \\
\text { North West } \\
\text { South East } \\
\text { South South } \\
\text { South West } \\
\text { Community poverty }\end{array}$ & $\begin{array}{l}3018 \\
2843 \\
4131 \\
1681 \\
3035 \\
2651\end{array}$ & $\begin{array}{l}2.2(3.1) \\
2.6(3.8) \\
2.7(3.9) \\
1.4(2.5) \\
1.6(2.6) \\
1.8(2.5)\end{array}$ & 68.3 & 0.000 \\
\hline $\begin{array}{l}\text { Low } \\
\text { Medium } \\
\text { High }\end{array}$ & $\begin{array}{l}4862 \\
5368 \\
7129\end{array}$ & $\begin{array}{l}3.1(4.0) \\
2.1(3.2) \\
1.6(2.6)\end{array}$ & 340.2 & 0.000 \\
\hline \multicolumn{5}{|c|}{ Proportion with high family-size norm in community } \\
\hline $\begin{array}{l}\text { Low } \\
\text { Middle } \\
\text { High } \\
\text { Community media ac }\end{array}$ & $\begin{array}{l}4009 \\
6025 \\
7325\end{array}$ & $\begin{array}{l}1.8(2.8) \\
2.2(3.3) \\
2.3(3.6)\end{array}$ & 28.3 & 0.000 \\
\hline $\begin{array}{l}\text { Low } \\
\text { Middle }\end{array}$ & $\begin{array}{l}4601 \\
5852\end{array}$ & $\begin{array}{l}2.9(3.9) \\
2.2(3.3)\end{array}$ & 240.8 & 0.000 \\
\hline http://aps.journals.ac.za & & & & 4410 \\
\hline
\end{tabular}


Table 3: Individual household and community contextual factors associated with children ever fathered in Nigeria, 2013

\begin{tabular}{|c|c|c|c|c|c|}
\hline Characteristics & Model 0 & Model I & Model 2 & Model 3 & Model 4 \\
\hline \multicolumn{6}{|l|}{ Ethnicity } \\
\hline Hausa & & I & & I & \\
\hline Igbo & & 1.00 & & $0.89 *$ & \\
\hline Yoruba & & $0.92 *$ & & $\left.0.9\right|^{*}$ & \\
\hline Others & & 1.00 & & $0.99 *$ & \\
\hline \multicolumn{6}{|l|}{ Age } \\
\hline $15-24$ & & I & & I & I \\
\hline $25-34$ & & $2.35 *$ & & $2.36 *$ & $2.39 *$ \\
\hline 35 and above & & $3.45 *$ & & $3.44 *$ & $3.50 *$ \\
\hline \multicolumn{6}{|l|}{ Educational Level } \\
\hline No education & & 1 & & 1 & \\
\hline Primary & & 1.02 & & 1.01 & \\
\hline Secondary & & 0.98 & & 0.96 & \\
\hline Higher & & $0.94^{*}$ & & $0.92 *$ & \\
\hline \multicolumn{6}{|l|}{ Occupation } \\
\hline Not working & & I & & I & \\
\hline Formal & & 1.14 & & 1.15 & \\
\hline Informal & & 1.10 & & 1.11 & \\
\hline Manual labour & & 1.09 & & 1.10 & \\
\hline \multicolumn{6}{|l|}{ Religion } \\
\hline Christianity & & I & & I & I \\
\hline Muslim & & 1.03 & & 1.04 & $1.05 *$ \\
\hline Traditional & & $1.10 *$ & & 1.10 & I.II* \\
\hline \multicolumn{6}{|l|}{ Frequency of reading } \\
\hline \multicolumn{6}{|l|}{$\begin{array}{l}\text { newspaper or } \\
\text { magazine }\end{array}$} \\
\hline Not at all & & I & & I & I \\
\hline Less than once a week & & 0.99 & & 0.98 & $0.97 *$ \\
\hline At least once a week & & $0.96 *$ & & $0.96 *$ & 0.93* \\
\hline \multicolumn{6}{|l|}{$\begin{array}{l}\text { Frequency of listening } \\
\text { to radio }\end{array}$} \\
\hline Not at all & & I & & I & I \\
\hline Less than once a week & & $1.07 *$ & & $1.07^{*}$ & $1.07 *$ \\
\hline At least once a week & & I.08* & & I.08* & $1.08^{*}$ \\
\hline \multicolumn{6}{|l|}{ Frequency of } \\
\hline Not at all & & I & & I & \\
\hline Less than once a week & & 0.99 & & 0.99 & \\
\hline At least once a week & & 0.98 & & 0.98 & \\
\hline \multicolumn{6}{|l|}{ Desired family size } \\
\hline $0-2$ children & & 1 & & I & I \\
\hline 3-4 children & & 0.93 & & 0.93 & 0.92 \\
\hline $5+$ children & & $1.12 *$ & & $1.13^{*}$ & $1.12 *$ \\
\hline \multicolumn{6}{|l|}{ Wealth index } \\
\hline Poorest & & I & & I & I \\
\hline Poorer & & $0.96 *$ & & $0.95^{*}$ & $0.95 *$ \\
\hline Middle & & $0.93 *$ & & $0.94 *$ & $0.92 *$ \\
\hline Richer & & $0.92 *$ & & $0.93 *$ & $0.90 *$ \\
\hline Richest & & $0.82 *$ & & $0.83^{*}$ & $0.79 *$ \\
\hline \multicolumn{6}{|l|}{ Number of spouses } \\
\hline 4411 & & & & http://aps.jou & iac.za \\
\hline
\end{tabular}


African Population Studies Vol 32, No. 3, Dec. 2018s

A wife

2-3 wives

Marital status

Married

Others

Age at first marriage

$10-17$

18-34

$35+$

Frequency of sexual

intercourse

Active in the last 4

weeks

Others

Time spent married

Less than I lyears

II-20 years

21 years and above

Contraceptive use

Currently using

Not currently using

Regions

South West

North Central

North West

North East

South East

South South

Place of residence

Urban

Rural

Ethnic diversity

Homogenous

Mixed

Heterogeneous

Community poverty

Low

Medium

High

Community level of education

Low

Middle

High

Proportion with high

family-size norm in

community

Low

Middle

High

Community media

access

Low

Middle

High
1

I.59*

2.26*

I.59*

1

2.23*

I.60*

$2.25 *$

1

I

1.03

1.05

1

$0.93 *$

0.84*

$0.93 *$

1

$0.84 *$

0.93*

0.83*

I.09*

I.08*

I.08*

I

I.80*

2.39*

$1.80 *$

I

2.39*

I.80*

2.39*

1

I.10*
I I

I.I0* I.09*

1

0.99

1

I

0.89

0.99

1.03

0.92

$0.52 *$

0.87

1.02

I.07*

I. $12^{*}$

I.12*

$1.17^{*}$

1.00

I.06*

I I

I.15* 1.01

I

$0.88^{*}$

1

0.93

I.01

I

$0.77^{*}$

1

1

$0.75^{*}$

0.99

0.98

0.94

0.96

1

$0.87 *$

I

I

$0.64 *$

I.10*

I.08*

I.09*

I.07* 


\begin{tabular}{|c|c|c|c|c|c|}
\hline $\begin{array}{l}\text { Random effects } \\
\text { Community-level }\end{array}$ & Empty & Individual/household & Community & Full model & Final model \\
\hline Variance (SE) & $0.28(0.02)$ & $0.01(0.00)$ & $0.09(0.01)$ & $0.01(0.00)$ & $0.01(0.00)$ \\
\hline $\mathrm{VPC}=\mathrm{ICC}(\%)$ & 7.8 & 0.3 & 2.7 & 0.3 & 0.3 \\
\hline $\begin{array}{l}\text { Explained variation } \\
\text { (PCV) \% } \\
\text { Individual/household- } \\
\text { level }\end{array}$ & Reference & 96.4 & 67.9 & 96.4 & 96.4 \\
\hline Variance (SE) & $2.5 \mid(0.05)$ & $0.01(0.00)$ & $2.50(0.05)$ & $0.01(0.00)$ & $0.01(0.00)$ \\
\hline $\begin{array}{l}\text { Explained variation } \\
\text { (PCV) \% }\end{array}$ & Reference & 99.6 & 0.4 & 99.6 & 99.6 \\
\hline $\begin{array}{l}\text { Log likelihood } \\
\text { Model fit statistics }\end{array}$ & -33251.2 & -15608.9 & -33040.4 & -15589.0 & -15743.6 \\
\hline $\mathrm{AlC}$ & 66508.4 & 31291.9 & 66118.9 & 31284.1 & 31555.2 \\
\hline $\mathrm{BIC}$ & 66531.7 & 31549.5 & 66266.4 & 31653.1 & 31792.3 \\
\hline
\end{tabular}

${ }^{*} \mathrm{p}<0.05, \quad \mathrm{SE}=$ standard error, $\mathrm{VPC}=$ variance partition coefficient, ICC=intra-class correlation coefficient, $\mathrm{PCV}=$ proportional change in variance

The empty model, which contains no explanatory variables, (Model 0) shows a significant variation in male fertility behaviour with variances ranging from 0.05 to $2.5 \mathrm{I}$ across individual levels, and variances ranging from 0.02 to 0.28 across communities, justifying the use of multilevel modelling. Model 0 indicated that the 'between communities variance' (expressed as variance partition coefficient -VPC or intra-class correlation coefficient -ICC) in the number of children ever born in 2013 was $7.8 \%$. This shows the observed variations associated with the number of children ever born.

In model I, the measure of variation did not yield significant variance across individuals (with variance ranging from 0.00 to 0.01 ) and across communities (with variance ranging from 0.00 to 0.01 ). The proportional change in variance (PCV) in Model I indicated that $96.4 \%$ of the variance associated with the number of children a man has ever fathered across communities was explained by individual/household variables.

A consideration of the measure of variation in model 2, fitting community-level variables into the model yielded a significant variance across individuals (with variance ranging from 0.05 to 2.50 ) and across communities (with variance ranging from 0.01 to 0.09 ). The proportional change in variance (PCV) in Model 2 indicated that $67.9 \%$ of the variance associated with the number of children a man has ever fathered across communities was explained by community variables.

Model 3 which is the full model indicated that the combination of all the variables (Individual, household and the community variables) in the multi-level model did not significantly change the number of children ever born. For instance, the exponential coefficient of the number of children ever born slightly declined among the lgbo in 2013 from I.00 (model I) to 0.90 (model 3); and 0.94 (model I) to 0.93 (model 3) among the Yoruba.

Furthermore, a comparison of the region of residence slightly changes among the models. The number of children ever born in the North East is as likely as the number of children in the South West (model I) but with a slight increase of $6 \%$ higher than the number of children in the South West in model 3.

Models with smaller values of an information criterion are considered preferable. In 2013, the full model (model 3) was preferably followed by the individual/household level model (model I). Fixed effects of model I show that the Yorubas were 0.92 as likely to have the number of children ever born as the Hausas. Ethnicity has a significant effect on a number of children a man has ever fathered.

Across the individual/household level characteristics, those aged $25-34$ were 135\% more likely than those aged 15-24 to have the number of children ever fathered while those who were older than 34 years were $245 \%$ more likely than those in the reference category. Age had significant effects on the number of children ever born. Education was another individual level considered. Model $\mathrm{I}$ in the table indicated that there was significant relationship between education and CEB among men. The table shows that respondents with the higher level of education were 0.94 as likely as respondents with no education to have the number of children ever born. Respondents who reported to have four to five wives were $126 \%$ more likely than respondents with one wife to have the number of children ever born. Moreover, marriage duration was significant. Men who had been married for more than twenty years were 139\% more than men who had spent less than eleven years to have their number of children ever born. 
All variables except occupation and frequency of watching television were significant while considering only the individual/household level. Men who listen to the radio at least once a week was $7 \%$ more likely than those who do not listen to it at all to have the number of children ever born. Respondents who reported not to be active in the past four weeks preceding the survey were $9 \%$ more likely than those who were sexually active in the last four weeks to have the number of children ever born.

Model two presented the community level variables in the relationship with CEB. In 2013, all the community level variables were significant. Men who hail from the North Central were 0.99 as likely as those who were from South West to have the number of children ever fathered. Rural dwellers have more children than urban dwellers. They were $15 \%$ more likely than those who reside in the urban settings to have children. Community level of education was rightly significant. Respondents who reside in the community with the high proportion of men with at least secondary education were $36 \%$ less likely than respondents who reside in the community with a low proportion of educated men to have children. Model 3 combined the simultaneous effects of the individual, household and the community level variables, the full model.

The final model (model 4) shows the variables that were significant with stepwise forward regression. In 2013, age of the respondents, religion, frequency of reading newspaper or magazine, frequency of listening to radio, desired family size, wealth index, number of spouses, age at first marriage, frequency of sexual intercourse, time spent married, contraceptive use, region of residence, community poverty and community education were significant with CEB. From the final model (model 4), respondents who live in the community with the high proportion of men and high poverty level were 0.96 as likely as those residing in the community with the low proportion of men and high poverty level to have the number of children ever fathered.

\section{Discussion and conclusion}

The pattern of male fertility behaviour shown by the mean number of children ever born revealed that men between the ages of 35 and above have the highest mean CEB. Considering educational level, the uneducated have the highest CEB and by religion, Muslims have the highest mean CEB. Results of highest CEB by Muslims could be due to the polygamous type of marriage. Consequently, from the results, men with four wives and above have the highest mean CEB. These results conform with the result of Odu et al's (2005) in their study on the semi-urban community in Nigeria. Their results reveal that the predictors of high fertility among men were low education, being a Muslim and having more than one wife. Finally, by regions, men from the North West have the highest mean CEB.

This study also determined the extent to which the characteristics of the community contexts explain variations in fertility behaviour among men. Results showed that the community level variables yielded a significant variance in the model. The number of children a man has ever born across communities was associated with community variables. This means that community variables such as the region of residence, type of place of residence, ethnic diversity, community-level education, community media access, community poverty level and community family size norm were significant in the study. More variation associated with the number of children ever born was explained by community variables. The data obtained from the study provided an insight into the determinants of male fertility in Nigeria. The full picture could be seen in the increased access to western education, modernisation, women equality, equity and empowerment, the advent of the economy and girl's education. It is further shown that there is need to develop our community to a better standard. This, in turn, will influence individual orientation on men's desired number of children.

The results shown above is in line with Easterlin and Crimmins model (1985) which consists of structural changes that affected the economic, social and political structures of the society in which they occur. Therefore, modernisation of the social and demographic structures can be linked to the level of social and demographic development. According to Easterlin and Crimmins (1985), modernisation involves significant alterations in fertility, mortality and migration as well as the place of residence, family size and structure, educational system, and in the provision for public health. Its influence extends further into the areas of income distribution, class structure, government organisation, and political structure. In terms of modernisation of human personality, it is characterised by an increased openness to new experience, increased independence from parental authority, belief in the efficacy of science and ambition from oneself and one's children.

Evidence has shown in the literature on the influence of community characteristics on infant and child mortality, maternal mortality, contraceptive use and female fertility (Adedini, et al, 2015, Ononokpono and Odimegwu, 20I4, Imasiku et al, 2014). Thus, this study extends the frontiers of knowledge by adding to literature that community contexts are statistically important for male fertility behaviour. This study concludes that community 
structures are to be considered in order to bring down the level of fertility in Nigeria.

\section{Limitations}

The data used for this study was collected from men between age 15-49 years. Also, the study was limited to the use of the available variables in the DHS data.

\section{References}

Adedini, S.A., 2013. Contextual determinants of infant and child mortality in Nigeria. PhD South Africa: University of the Witwatersrand.

Adedini, S.A., Odimegwu, C., Imasiku, E.N.S., Ononokpono, D.N., Ibisomi, L., 2015. Regional variation in infant and child mortality in Nigeria: $A$ multilevel analysis. Journal of Biosocial Science,47 (02), pp. 165-I87.

Alich, D., 2007. Differences between male and female fertility in Russia - an evaluation of basic pattern and data quality using the first wave of the Russian GGS. Working paper at Max Planck Institute for Demographic Research Konrad-ZuseStrasse I.

Babalola, Stella, \& Fatusi, Adesegun., 2009. Determinants of use of maternal health services in Nigeria - looking beyond individual and household factors. BMC Pregnancy and Childbirth, 9(I), pp. 43.

Billy, J., and Moore, D.E., 1992. A Multilevel Analysis of Marital and Non-marital Fertility in the U.S. Social Forces, 70 (4), pp. 977-I0I I.

Becker, S., 1996. Couples and Reproductive Health; a Review of Couples Studies. Stud FamPlann, 27(6), pp. 29I-306.

Boco A. G., 20I0. Individual and community level effects on child mortality: an analysis of 28 Demographic and Health Surveys in sub-Saharan Africa. DHS Working Papers No. 73 ICF Macro, Calverton, MD, USA.

Bongaarts, J., 1978. A framework for analyzing the proximate determinants of fertility. Population and Development Review, 4(I), pp. I05-132.

De rose A., and Racioppi F., 200I. Explaining voluntary low fertility in Europe: a multilevel approach. Genus, January - March, 57(I), pp. I332.

Easterlin, R. A., and Crimmins, E. M., 1985. The fertility revolution: A supply-demand analysis. The University of Chicago Press, Chicago, pp xix + 209.

Udjo E.O., (2018). Effect of HIV/AIDS on fertility: historical evidence from South Africa's women educators, Africa Population Studies. Vol 32, No 2.
Farzaneh R., Lori A., 1996. Men and family planning in Africa. Population Reference Bureau. Washington DC, pp. 3-23.

Imasiku E.N.S, Odimegwu C.O, Adedini S.A, Ononokpono D.N., 20l4. Variations in unmet need for contraception in Zambia: does ethnicity play a role? Journal of Biosoc Sci., 46, pp. 294315.

Mason K., Lynam P., 1992. Not for women only: child- spacing clubs for Malawian men. AVSC News, 30(4) p. 4.

Mbizvo M.T, Adamchak D.J., |99I. Family planning knowledge, attitudes and practices of men in Zimbabwe. Stud Fam Plann, vol. 22, pp. 31-38.

Mistik S.,Nacar M., Mazicioglu M., and Centinkaya F., 2003. Married men's opinions and involvement regarding family planning in rural areas. Contraception, 67, pp. I33-I37.

Morris L., 1993. Determining male fertility through surveys: young adult reproductive health surveys in Latin America. Paper presented at International Union for the Scientific Study of Population [IUSSP] Conference, Canada.

Odimegwu, C., Pallikadavath, S., \& Adedini, S., 20I3. The cost of being a man: social and health consequences of lgbo masculinity. Culture, health \& sexuality, 15(2), 219-234.

Odu O.O., ljadunola K.T.I., and Parakoyi D.B., 2005. Reproductive behaviour and Determinant of fertility among men in a semi-urban Nigerian community. Journal of community Medicine and Primary Health Care, I7(I), pp. I3-19.

Ononokpono D.N and Odimegwu C.B., 2014. Determinants of maternal health care utilization in Nigeria: a multilevel approach. Pan Africa Medical Journal, I 7(Supp I):2

Osazuwa Peter I \& Ugal David (20|8). A comparative study of fertility preferences of Nigerian female migrants and non-migrants in Benin City, Nigeria. Africa Population Studies. Vol 32, No 2.

Oyediran K.A., Ishola G.P., Feyisetan B.J., 2002. Factors affecting ever-married men's contraceptive knowledge and use in Nigeria. J Biosoc Sci, 34(4), pp. 497-5 I0.

Population Reference Bureau, 2016. Human Population: Population Growth http://www.prb.org/Publications/LessonPlans/Hu manPopulation/PopulationGrowth.aspx

Rindfuss, R. R., Morgan, P., \& Offutt, K., 1996. Education and the changing age pattern of American fertility: 1963-1989. Demography, 33(3), pp. 277-290.

Schoumaker, B., 2013. Levels and Patterns of Male Fertility in Sub-Saharan Africa: What can we learn from the Demographic and Health Surveys? 
African Population Studies Vol 32, No. 3, Dec. 2018s

Paper presented at the PAA meeting, New Orleans.

Smith-Lovin, L., \& Tickamyer, A. R., 1978. Nonrecursive models of labour force participation. fertility behaviour and sex role attitudes. American Sociological Review, 43(4), 54I-557.
United Nations, Department of Economic and Social Affairs, Population Division, 2014. World Fertility Report 2013: Fertility at the Extremes (United Nations publication)

Zhang, L., 20II. Male Fertility Patterns and Determinants, Dordrecht, Springer. 